\title{
REPRESENTAÇÕES DA ALTERIDADE FEMININA EM TO ROOM NINETEEN, DE DORIS LESSING
}

Resumo: A literatura, como arte que representa a experiência humana, por vezes, esteve engajada na busca da emancipação daqueles que a sociedade oprime. Recentemente, o tema da figura da mulher e de sua luta para viver em uma sociedade patriarcal vem ganhando destaque principalmente devido aos avanços do movimento feminista. Assim, muitas escritoras e escritores passaram a ter como tema a figura da mulher. Dessa forma, Doris Lessing vem recebendo atenção especial pelo modo como apresenta as suas personagens e suas lutas diárias por uma vida melhor. Nesse sentido, o presente artigo tem como objetivo traçar reflexões acerca da figura da mulher representada em um dos contos mais famosos da escritora: To room nineteen. Para tanto, tomaremos como base estudos de Simone de Beauvoir e de Eric Landowski.

Palavras-chave: Representação feminina. Alteridade. Doris Lessing. To room nineteen.

Abstract: Literature, as a means of art that represents human experience, has always been engaged in the search for emancipation of those oppressed by the society. Recently, the female figure theme and their struggle to live in a patriarchal society have been receiving attention mainly due to the advances of the feminist movement. In this sense, many writers have focused on writing about this theme. That way, Doris Lessing has received special attention due to how she represents her characters and their everyday struggle to a better life. So, the present article aims at reflecting about the female figure represented in one the Lessing's most famous short-stories: To room nineteen. In order to do so, our article will be based on studies by Simone de Beauvoir and Eric Landowski.

Keywords: Feminine representation. Alterity. Doris Lessing. To room nineteen.

\section{INTRODUÇÃO}

Com o advento da modernidade e o avanço nos estudos dos direitos humanos, muito passou a se discutir sobre aqueles que não tiveram as mesmas oportunidades dos que estão no poder. Historicamente, sabe-se que o

${ }^{1}$ Mestranda em Estudos Literários do Programa de Pós-Graduação em Letras da UFSM. Bolsista CAPES. E-mail: larissa-garay@hotmail.com 
poder sempre esteve (e ainda está) nas mãos do homem de etnia branca. Assim, como forma de tentar reverter esse problema histórico, os estudos feministas, assim como de todos os oprimidos, como os negros, homossexuais e imigrantes, entraram em cena. Segundo Eric Landowski (2002, p. 4), a questão de como encaixar o 'outro' na sociedade vem ganhando cada vez mais atenção:

\begin{abstract}
A uma das perguntas mais ambiciosas feitas neste fim de século no plano politico - a do reconhecimento ou da eventual formação de uma "identidade europeia comum" - superpõe-se assim outra, menos carregada de ideal, mas ditada de urgência: que lugar, no interior de si mesma, cada uma das sociedades nacionais envolvidas nesse vasto projeto de unidade político-cultural estará em condições de conceder ao que parece atualmente estar se tornando sua parte maldita: ao Outro, qualquer que seja localmente seu modo de encarnação crítico?
\end{abstract}

Como Landowski (2002) bem exemplifica, há uma urgência em recolocar na sociedade aqueles que por muito tempo não tiveram voz. Não somente isso: é preciso que o outro seja reinserido na sociedade como um ser crítico para que, assim, possa se tornar ser agente autônomo de sua vida. Nesse sentido, um dos movimentos que mais tem ganhado força nos últimos anos foram os estudos feministas.

Os estudos feministas tiveram início em meados do século XX. Segundo os críticos da área feminista, há várias vertentes desses estudos, entre elas a daqueles que acreditam que a construção do entendimento do ser humano se dá através de suas condições biológicas, e aqueles que acreditam que tudo é uma construção da sociedade. Assim, Simone de Beauvoir ficou famosa ao dizer a célebre frase que afirma que não se nasce mulher, mas, sim, torna-se mulher. Como é possível perceber, para a escritora, a nossa percepção de mundo se dá através de construções culturais. Ou seja, o modo como somos criados influencia diretamente o modo que nos enxergaremos no mundo e também como perceberemos o papel do outro.

Não por acaso, portanto, que a literatura é um espaço privilegiado de expressão de luta contra as desigualdades. Obviamente, desde que a literatura é produzida já havia sinais de escritores e escritoras que se posicionavam 
contra as injustiças sofridas pela mulher. No entanto, só recentemente as mulheres têm sido reconhecidas como grandes escritoras e representantes de suas classes. Na verdade, isso ocorria devido ao fato de que, no passado, havia muita censura e as mulheres não possuíam independência e, por vezes, estudo suficiente para serem capazes de se expressar.

Dentre as tantas vozes que se incumbiram de representar os sentimentos femininos mais profundos está Doris Lessing, que é, atualmente, muito reconhecida pela crítica literária por seus contos e romances que falam da vida contemporânea e de suas injustiças. Nascida na Pérsia, atual Irã, sempre vivera uma vida diferente das mulheres à sua volta. Sempre incentivada a estudar, ela teve acesso ao que poucas senhoras tinham em meados do século XX: conhecimento.

Naturalmente, acostumada com as injustiças que via as mulheres de sua época sofrerem, Lessing tornou-se uma das representantes mais competentes das causas feministas. Não é de se estranhar, portanto, que tenha ganhado o premio Nobel de Literatura em 2007. Um dos seus contos mais famosos que, por acaso, também lida com as opressões sofridas pelas mulheres, é To room nineteen, que publicado em 1978, apresenta um enredo basicamente simples: Susan, esposa dedicada, resolve largar seu emprego pelo bem de seus filhos e seu casamento. Assim, a narrativa gira em torno do modo como Susan é oprimida pelo casamento, seus filhos e, principalmente, seu marido. Nesse sentido, o presente artigo tem como objetivo levantar reflexões acerca da personagem principal, Susan, e o modo como sua personalidade vai se apagando aos poucos devido à rotina do casamento.

\section{A REPRESSÃO LEVADA À ÚlTIMA INSTÂNCIA EM TO ROOM NINETEEN: SUSAN E O PAPEL FEMININO NO CASAMENTO}

Susan e Matthew Rawlings casaram-se no final de seus vinte anos. Segundo a voz narrativa, antes de casarem, ambos viviam uma vida boa e agradável. Susan, que é o objeto de análise desse artigo, é descrita como uma pessoa bem humorada e bem sucedida. Aliás, antes do casamento, é possível perceber que Susan e Matthew viviam uma vida mais tranquila, já que ambos 
tinham a sua independência: "Both, before they married, had had pleasant flats, but they felt it unwise to base a marriage on either flat, because it might seem like a submission of personality on the part of the one whose flat it was not." (Lessing, 199- ?, p. 526). Assim, como é possível perceber, Susan foi perdendo a sua autonomia na medida em que eles ficaram mais tempo juntos.

Nesse sentido, quando Susan engravidou, ela largou seu emprego e o casal foi morar em uma casa em Richmond. Por isso, Susan passava seus dias cuidando das crianças do casal. No entanto, esperava ansiosamente pelo momento em que pudesse voltar a trabalhar. É possível perceber, logo no início da narrativa, que Susan não vive sua vida plenamente. Apesar de estar aparentemente feliz com o seu casamento e a vida de dona de casa, ela passa seus momentos esperando pelo futuro:

\begin{abstract}
Nor did Susan make the mistake of taking a job for the sake of her independence, which she might very well have done, since her old firm, missing her qualities of humour, balance, and sense, invited her often to go back. Children needed their mother to a certain age, that both parents knew and agreed on; and when these four healthy wisely brought up children were of the right age, Susan would work again, because she knew, and so did he, what happened to women of fifty at the height of their energy and ability, with grownup children who no longer needed their full devotion. (Lessing, 199- ?, p. 527)
\end{abstract}

Naturalmente, Susan foi a única a abrir mão de algo para o bem do casamento. Como podemos perceber, ela abre mão de sua independência pelo bem das crianças. Não é de se estranhar, portanto, o motivo pelo qual a voz narrativa informa ao leitor, logo no início do conto, que esta seria uma história sobre uma falha de inteligência.

Aliás, Simone de Beauvoir (1980) esclarece que o fato de a mulher abrir mão de tantas coisas e, principalmente de sua liberdade, pelo bem do casamento e da sua relação com o homem é uma de suas maiores traições para com si mesma:

A primeira traição da mulher: a da própria vida que, embora assumindo as formas mais atraentes, é sempre habitada pelos fermentos da velhice e da morte. O próprio uso que o homem faz dela destrói suas virtudes mais preciosas: gastas pelas maternidades, ela perde sua atração erótica; mesmo estéril, bastam os anos para alterar-Ihe os encantos. Enferma, feia, velha, a mulher causa horror. (Beauvoir, 1980, p. 202) 
$\mathrm{Na}$ verdade, em To room nineteen podemos perceber ambas as afirmações de Beauvoir. A primeira diz respeito ao fato de Susan abrir mão de sua liberdade pelo bem do casamento e dos filhos; a segunda, por sua vez, é tão grave quanto: Susan abre mão da fidelidade de seu marido: "It was banal, too, when one night Matthew came home late and confessed he had been to a party, taken a girl home and slept with her. Susan forgave him, of course. Except that forgiveness is hardly the word. Understanding, yes." (Lessing, 199?, p. 528). Desse modo, podemos afirmar que Susan já havia se tornado uma pessoa submissa às vontades de seu marido. Assim, o casamento já havia a afetado: antes ela era capaz de argumentar que deveriam morar em outro flat que não o deles, pois somente assim ninguém teria que passar por uma submissão de personalidade. Agora, por outro lado, Susan já não possui mais voz.

Assim, Susan que já vive uma vida na qual sua única felicidade está nos momentos que seus filhos estão fora de casa e ela pode ficar em liberdade, também diz a Matthew que tem um caso. Aparentemente, Susan tenta chamar a atenção de Matthew, que descobre que ela tem passado suas tardes em um quarto de hotel barato. Ao invés de contar a verdade a Matthew, Susan alega que tem um amante:

She began slowly, careful not to contradict herself: "His name is Michael" (Michael What?) - 'Michael Plant.' (What a silly name) "He's rather like you, in looks, I mean." And indeed, she could imagine herself being touched by no one but Matthew himself. "He's a publisher." (Really? Why?) 'He's got a wife already and two children." (Lessing, 199- ?, p. 546)

No entanto, Matthew - que agora já possui outra amante absurdamente sugere que os quarto saiam para almoçar juntos. Assim, podemos perceber que Susan tenta chamar a atenção de Matthew, e ele a ignora totalmente. Além de tudo, Susan sofre não só pela falência de seu casamento, mas também pelo fato de amar Matthew loucamente e só conseguir se imaginar sendo tocada por ele.

Como podemos perceber, Susan estava cada vez mais perdendo a sua voz e sendo assolada por uma falta de liberdade e atenção. Assim, sua única 
solução se dá na exclusão: ela decide passar um tempo no quarto 19 de um hotel barato, pois lá era a única maneira que ela poderia fugir da realidade. Desse modo, Susan passa a se isolar cada vez mais de sua vida medíocre. Aliás, Lawdowski (2002, p. 22) argumenta que a exclusão é algo comum nos grupos minoritários. Muitas vezes a exclusão se dá devido à opressão dos grupos majoritários que, às vezes, ocupam a posição de hospedeiro. Como podemos perceber, Susan é tão oprimida em sua própria casa que a única forma de se sentir livre é buscando abrigo em outro lugar.

Assim, o quarto dezenove, onde Susan passa a ir frequentemente, torna-se, cada vez mais, como um momento de escape de sua vida vazia. Para Susan, esse era o único local em que ela se sentia livre:

\begin{abstract}
What did she do in the room? Why, nothing at all. From the chair, when it had rested her, she went to the window, stretching her arms, smiling, treasuring her anonymity, to look out. She was no longer Susan Rawlings, mother of four, wife of Matthew, employer of Mrs. Parkes and of Sophie Traub; with these an those relations with friends, school-teachers, tradesmen. She no longer was mistress of the big white house and garden, owning clothes suitable for this and that activity or occasion. She was Mrs. Jones, and she was alone, and she had no past and no future. Here I am, she thought, after all these years of being married and having children and playing those roles of responsibility-and I'm just the same. Yet there have been times I thought that nothing existed of me except the roles that went with being Mrs. Matthew Rawlings. (Lessing, 199- ?, p. 542)
\end{abstract}

De fato, Landowski (2002, p. 22) aponta que a perda da identidade é um dos fenômenos mais comuns na vida daqueles que são oprimidos. Como podemos perceber, Susan deseja voltar a ser a pessoa que era quando ainda solteira. Assim, tal referência pode ser entendida pelo viés de que, quando era solteira, Susan ainda podia fazer as suas próprias escolhas, diferentemente da sua vida de casada na qual ela precisa esperar seus filhos saírem da escola para retornar ao seu emprego e à liberdade.

Nesse sentido, o final da narrativa não surpreende a ninguém. Imersa em uma vida que não a satisfaz, com a sua dignidade e identidade perdida, Susan encontra a solução no suicídio. Desse modo, para Susan, o suicídio caracteriza-se como uma forma de escape, de salvação, posto que é através dele que seu sofrimento termina. 
É interessante perceber, também, o modo como Susan decide por fim a sua vida. Ela faz uso de um gás para que, assim, sua morte possa ser calma e sem os horrores do sangue. No entanto, também em sua escolha de como se suicidar, opta por aquela que tira a sua voz, pois o gás enche seus pulmões e ela não consegue gritar. Mais uma vez, portanto, Susan não consegue ter sua voz ouvida.

Como é possível perceber, a narrativa que nos é apresentada por Doris Lessing parece levar ao extremo a dor de uma mulher oprimida por seu marido e pelo casamento. No entanto, Susan parecia não ter escolha além daquela que encontrou, pois já não havia modo de conversar com seu marido e ser ouvida. Assim, ela encontra sua própria saída de uma sociedade patriarcal, machista e repressora.

\title{
3. COMENTÁRIOS FINAIS
}

O conto To room nineteeen é um dos mais aclamados de Doris Lessing. Não por acaso, de fato, uma vez que a história da pobre Susan é ainda muito atual e recorrente, mesmo depois de mais de 30 anos de sua publicação. $\mathrm{Na}$ verdade, a temática da opressão sofrida pelas mulheres no casamento parece ter se tornado um tema recorrente para as escritoras do século XIX. Assim, podemos perceber como a nossa sociedade tem dado passos em direção a um futuro talvez mais promissor e justo no sentido de igualdade de gêneros.

Antes de Doris Lessing começar a representar as mulheres, Simone de Beauvoir já nos ensinava que nos tornamos mulheres devido às construções sociais. Segundo Beauvoir:

\begin{abstract}
A mulher tem um duplo e decepcionante aspecto: ela é tudo a que o homem aspira e tudo o que não alcança. [...] Serva e companheira, ele espera que ela seja também seu público e juiz, que ela o confirme em seu ser; mas ela contesta-o com sua indiferença, e até com seus sarcasmos e risos. Ele projeta nela o que deseja e o que teme, o que ama e o que detesta. E se é tão difícil dizer algo a respeito é porque o homem se procura inteiramente nela e ela é Tudo. Só que ela é Tudo à maneira do inessencial: ela é todo o Outro. (1978, p. 242)
\end{abstract}

Assim, é preciso que a luta continue para que, algum dia, nossa sociedade respeite os direitos humanos com veemência e, casos semelhantes 
ao de Susan, fiquem no passado. Para tanto, é necessário que escritoras como Doris Lessing nos brindem com suas narrativas que, apesar de chocantes, mostram a realidade diária de milhares de mulheres que desistiram de sua independência em prol de um casamento feliz.

Curiosamente, ainda hoje, tempo em que as mulheres adquiriram diversos direitos semelhantes ao dos homens, sabemos seguidamente de casos de suicídio e violência contra o sexo feminino. É por isso que a narrativa de Susan precisa ser levada adiante, pois a literatura também tem o papel de ensinar a sociedade através de histórias que às vezes não teríamos acesso se não fosse por ela. Desse modo, poderemos ver o dia em que não existirão mais 'Susans' em nosso mundo real, mas, somente no mundo onde elas sempre deveriam ter ficado: na ficção.

\section{REFERÊNCIAS}

BEAUVOIR, Simone de. O segundo sexo. Tradução Sérgio Milliet. Rio de Janeiro: Nova Fronteira, 1980.

LANDOWSKI, Eric. Presenças do Outro: ensaios de sociossemiótica. Tradução Mary Amazonas Leite de Barros. São Paulo: Editora Perspectiva, 2002.

LESSING, Doris. To room nineteen, 199- ?. Disponível em: <http://litandplacesp2011.qwriting.qc.cuny.edu/files/2011/02/To-Room-19Lessing.pdf. Acesso em: 09 fev. 2015. 